\title{
TRAVEL TIME OBSERVATIONS USING BLUETOOTH MAC ADDRESS MATCHING: A CASE STUDY ON THE RAJIV GANDHI ROADWAY: CHENNAI, INDIA
}

\author{
by \\ Stephen M. Remias \\ Asst. Professor \\ Ph.D. in Civil Engineering \\ Wayne State University \\ 5050 Anthony Wayne Dr. \\ Detroit, MI 48202 \\ sremias@wayne.edu \\ Alexander M. Hainen \\ Asst. Professor \\ Ph.D. in Civil Engineering \\ University of Alabama \\ Box 870205 \\ Tuscaloosa, AL 35487 \\ ahainen@eng.ua.edu \\ Jijo K. Mathew \\ Ph.D. Student \\ M.Tech in Civil Engineering \\ Purdue University \\ 550 Stadium Mall Drive \\ West Lafayette, IN 47907 \\ kjijo@purdue.edu \\ Lelitha Vanajakshi* \\ Associate Professor \\ Ph.D. in Civil Engineering \\ IIT Madras \\ Transportation Engineering Division \\ Dept of Civil Engineering \\ Chennai, Tamil Nadu 600036. \\ lelitha@iitm.ac.in \\ +91-44-2257 $4291(\mathrm{O})$ \\ Anuj Sharma \\ Associate Professor \\ Ph.D. in Civil Engineering \\ Iowa State University \\ Ames, IA 50011 \\ anujs@iastate.edu \\ Darcy M. Bullock \\ Professor \\ Ph.D. in Civil Engineering \\ Purdue University \\ 550 Stadium Mall Drive \\ West Lafayette, IN 47907 \\ darcy@ purdue.edu \\ *Corresponding author - Email: lelitha@iitm.ac.in
}




\title{
TRAVEL TIME OBSERVATIONS USING BLUETOOTH MAC ADDRESS MATCHING: A CASE STUDY ON THE RAJIV GANDHI ROADWAY: CHENNAI, INDIA
}

\begin{abstract}
Bluetooth MAC Address matching has become a useful approach for determining travel times on corridors in the United States. In September 2013, an international collaborative study was performed using this technology along a busy urban corridor in Chennai, India. Two Purdue University graduate students traveled to Chennai, India to interact and understand the dynamics of exchanging knowledge and implementing technologies in different environments. The students worked with students from IIT Madras to determine the feasibility of Bluetooth probe vehicle technology along a typical Indian corridor. The study determined that it is feasible to expand Bluetooth use in India. Using the technology, the impact of weather, holiday and peak hour related traffic events were determined and evaluated. Of particular note were the relative high penetration of Bluetooth devices, and the exceptionally strong impact of precipitation on the heterogeneous traffic stream in Chennai, India.
\end{abstract}

Keywords: Travel time, Reliability, Bluetooth, Raspberry Pi, Driving Behavior 


\section{INTRODUCTION}

Travel time and its variability are two of the most popular indicators of the quality of traffic. They are also major parameter of interest in various ITS applications. It assists the road users in making timely decisions regarding their trip such as departure time, mode choice, route choice etc. In order to measure travel time, the vehicles have to be continuously tracked or re-identified at various locations. This can be achieved through by several technologies including Automatic License Plate Readers (ALPR), electronic tag identifiers, probe vehicles and video image processing. However, the lack of lane discipline and the vast number of heterogeneous vehicle classes makes it very difficult to measure travel time in Indian conditions with technologies using infrastructure mounted sensor trying to detect and re-identify vehicles. Technologies present within the vehicles broadcasting or logging its presence and identity are more effective as the onus of actual detecting a vehicle is eliminated. Currently, GPS units deployed in the public transport buses are the primary source of travel time information. However, the buses account for only $1 \%$ of the total traffic in most of the cities. Moreover, under heterogeneous traffic conditions, the data from bus alone will not be enough to capture the characteristics of the stream having vehicles of completely different characteristics. Another disadvantage is that the GPS data can be obtained only from bus routes, missing out other routes. Use of GPS units in other modes is restricted due to the associated privacy issues. Thus, there is a need for different sensors for travel time data collection, which can collect data from different modes and from all roads of interest. Capturing anonymous Bluetooth data provides an opportunity to collect data that is representative of a variety of vehicles classes on moderately and heavily travelled roadways.

Bluetooth is a wireless telecommunications standard used for short-range data exchange in many consumer products such as laptops, mobile phones, personal navigation devices, audio-video players and headsets. It uses the $2.4 \mathrm{GHz}$ short-range radio frequency spectrum, which it divides into 79 channels of 1 $\mathrm{MHz}$ bandwidth each to transmit data. In order for one Bluetooth device to find another, it needs to send inquiry packets. Devices that are in a discoverable state will scan these channels and respond to the inquiry. Bluetooth radios are classified into three groups based on their communication range: Class 3 has a range of up to 1 meter, Class 2 up to 10 meters, and Class 1 up to 100 meters. However, only a minimum range is mandated by the Bluetooth specification and manufacturers can tune their devices for the required ranges. Most devices observed on the highways use power levels that are close to or more than Class 1 range.

The Bluetooth protocol uses a unique 48-bit electronic identifier known as the Media Access Control (MAC) address for each device, in the form of "12:34:56:78:90:ab". The first three octets "12:34:56" represent the Organizationally Unique Identifier (OUI) which gives information on the manufacturer and the last three "78:90:ab" are assigned by the manufacturer in order to give a unique address to the device. The Bluetooth transceivers transmit their MAC addresses for the purpose of identifying other devices. This inquiry mode is used to establish a link with responding devices. Inquiries can be made to a device even when it is engaged in communication to another device. When a device communicates with another, it responds to the inquiry scan with its MAC address and clock information (www.bluetooth.com/basics). This facilitates the identification of Bluetooth enabled devices in vehicles, provided the discovery of the device is enabled. If the same address is detected at two different locations, the time difference between the two detections can give the time taken to travel that stretch. Also, the speed can be computed, given the distance between the two sites is known. Aggregating results from multiple devices can be used to estimate the average travel time and speed along the corridor. 
Travel time estimation via Bluetooth sensors is very popular due to its cost-effectiveness and ease of installation. The number of Bluetooth devices in vehicles is also expected to grow over time, thereby making it a promising alternative to the traditional travel time measurement technologies. This paper studies the use of Bluetooth sensors as traffic data collection devices under Indian conditions, taking a representative road stretch in Chennai, India as the study area. The study covers penetration rate analysis, the type of devices detected, comparison of the performance of difference sensors, and detailed analysis of the travel time along the study site. The study tries to capture the variation in driving behavior and travel times along the corridor in a week which comprised of public holidays, normal working days with varying weather conditions and weekends.

\section{LITERATURE REVIEW}

The use of Bluetooth Monitoring Stations has been a well-documented procedure in the United States [1-9]. Wasson et al. reports on the use of a prototype system to collect and match MAC addresses at different locations [1]. Not only were the travel time trends easy to discern by visual inspection, but also the feasibility of estimating travel time using such a technology was very high. Bluetooth technology was found to be a promising method for reliable high quality travel time estimates, which can be used as a ground truth for evaluating other sensors [2]. Brennan et al. conducted a sensitivity analysis to study the influence of vertical placement of sensor on data collection efficiency from Bluetooth MAC addresses [3]. They found that the efficiency of capturing MAC addresses is sensitive to the antenna height and recommended an antenna height of above $8 \mathrm{ft}$. Studies using statistical methods have shown that the travel times estimated using Bluetooth can be used to predict the average travel time and travel time variability with reasonable accuracy [4]. Other Bluetooth studies include travel time delay in work zones [5], estimating route choice and travel time reliability [6] and origin - destination studies [7]. Studies have also reported that the MAC address matching method for travel time estimation is cost-effective compared to other traditional methods [8].

The uses of the data have included determining travel times along freeway and arterial corridors, determining vehicle route choice, performing work zone speed studies, and measuring pedestrian delays at airports. The Bluetooth data is incredibly relevant because it can be adapted to perform many different functions. In the United States, a significant reduction in Bluetooth data fidelity has occurred in recent years. This may be due to many new Bluetooth devices defaulting to a non-discoverable mode, meaning the devices will not emit a signal that can be collected by the data sensors. This reduction in Bluetooth data in the United States leads to questions regarding other countries data fidelity. Bluetooth Monitoring Studies have also been used in other nations with great success. These countries include Australia [10], China [11], and Belgium [12]. The purpose of this study is to examine the fidelity and usefulness of Bluetooth data in India, which is the second most populous country in the world.

\section{STUDY LOCATION}

The road stretch from Sardar Patel Road to the Tidel Park intersection via the Rajiv Gandhi Salai in Chennai having a total length of $2.4 \mathrm{~km}$ was chosen as the study site (Fig 1). The Sardar Patel Road and Rajiv Gandhi Salai are 6 - lane roadways, with 3 lanes in each direction and each having a width of 3.5m/lane. Major part of the traffic from Sardar Patel Road takes a right turn at the signal controlled Tshaped Madhya Kailash intersection and enters into the Rajiv Gandhi Salai. A part of the flow enters as the free left turn traffic coming from the opposite direction. There is a local railway line that runs parallel to 
the road stretch along the Madhya Kailash - Tidel Park direction. This roadway is also known as 'IT corridor' since Information Technology industries occupy most of the area. The study site also houses a number of automated sensors, the data from which were used to estimate the daily traffic. The road stretch has an ADT of more than 100,000 vehicles per day with the morning peak occurring in the northbound direction from Sardar Patel Road to Tidel Park and the evening peak occurring in the opposite direction. Fig 1 shows a layout of the study site.

Bluetooth Monitoring Stations (BMS) were setup along the study corridor as shown in Fig 1. BMS 1 was deployed at around $350 \mathrm{~m}$ before the Madhya Kailash intersection while BMS 6 was placed just after the Tidel Park intersection. BMS 3, 4 and 5 were placed at the first, second and third Foot Over Bridges (FOB) along the Rajiv Gandhi Salai. The units were placed at a height of 6 feet from ground on lamp posts or bridge columns as can be seen in Fig 2 .

Three different types of Bluetooth sensors were used in this study to compare the performance Traffax BlueFax, Raspberry Pi and an Android phone based Bluetooth sensor. Traffax BlueFax is a portable Bluetooth sensor developed at the University of Maryland for traffic monitoring (http://www.traffaxinc.com/). The Raspberry Pi is a small credit card sized computer board working in Linux operating system which was coded to capture Bluetooth devices. The Android phone based Bluetooth sensor is an application developed to record the Bluetooth devices identified by the phone while in normal use. Traffax and Raspberry Pi used a Class 1 Bluetooth adapter (SENA Parani UD-100) equipped with a $13 \mathrm{dBi}$ antenna whereas the Android phone had the default in-built Class 2 sensor.

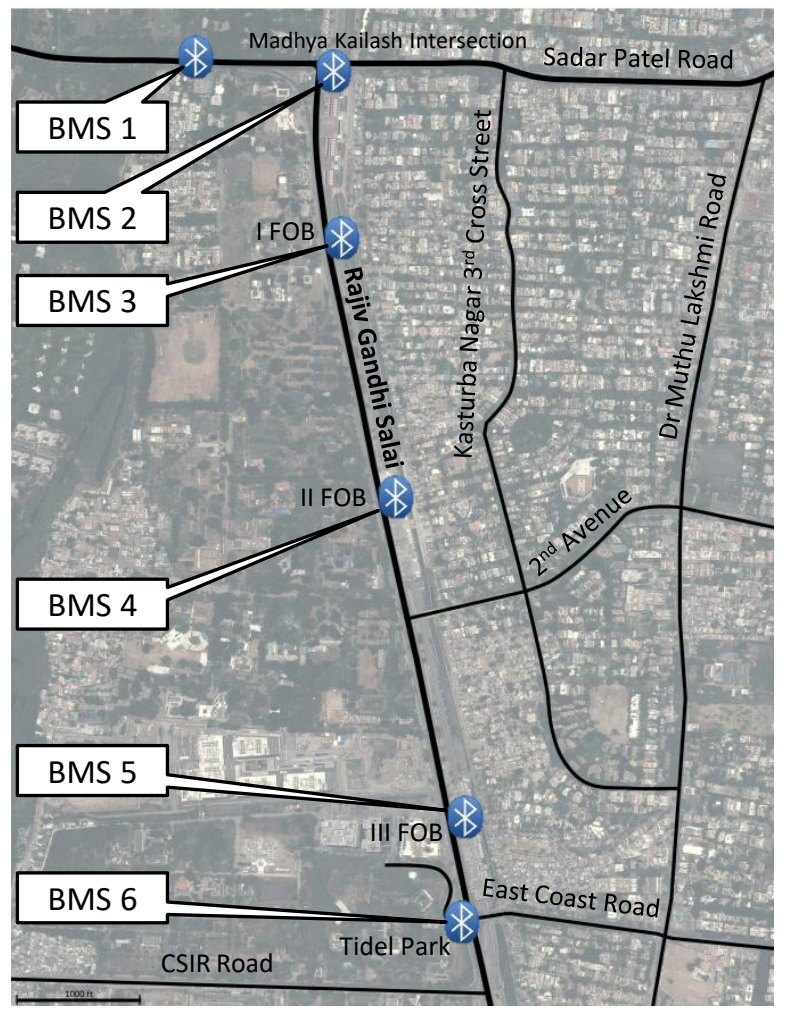

Fig 1 Study corridor and location of Bluetooth Monitoring Stations 


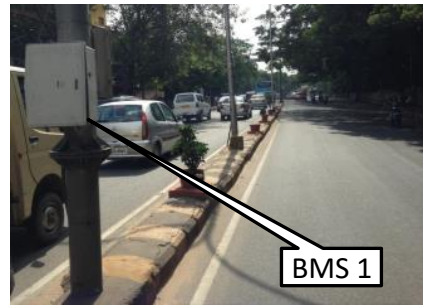

a. BMS 1

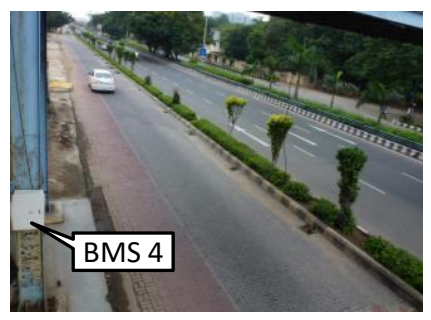

c. BMS 4

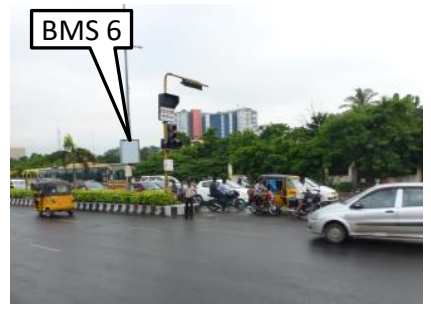

e. BMS 6

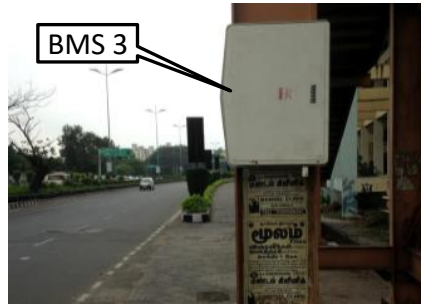

b. BMS 3

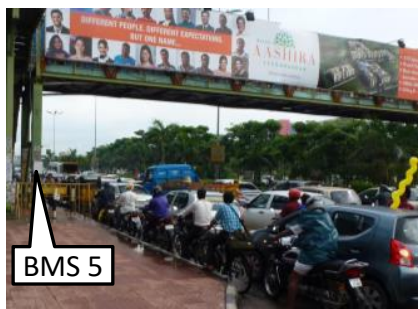

d. BMS 5

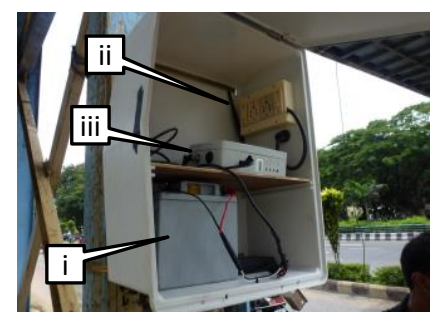

f. BMS install

Fig 2 Bluetooth Monitoring Stations ((a) - (e) shows the BMS at different locations. (f) shows a typical BMS with (i) battery to supply power, (ii) $13 \mathrm{dbi}$ antenna and (iii) host machine)

\section{FIELD DATA OBSERVATIONS}

Data were collected for 24 hours over a week from September 7 to 13, 2013. The sensors scan for all the visible devices within its range and store their MAC address along with the timestamps. In addition to this, the Raspberry pi unit output included information on the type of device being identified. Preliminary analyses of the data obtained included device identification, data quality checks and a general trend analysis of travel time in both directions before carrying out the detailed analysis of travel time characteristics.

\subsection{Data Quantities}

The data were collected along a 2.4 kilometer section of the Rajiv Gandhi Salai in Chennai, India. Five Bluetooth Monitoring Stations (BMSs) were deployed for a week of data collection. Table 1 shows the number of MAC addresses collected at each site. The devices were deployed on Saturday (9/7) and collected on Friday (9/13), so those days had significantly less data. Monday (9/9) was a holiday in India, which also resulted in less data collection than a typical day. Tuesday (9/10) is shown to demonstrate a typical day of data collection. The total number of records collected during the study period exceeded 1.5 million MAC addresses that could be used for matching. The number of unique MAC addresses collected at each site over the entire study period is also listed in the table. BMS 1 has the highest number of MAC addresses because of its location on a high volume segment of roadway. BMS 4 had a failure mid-week, resulting in no data collection from Wednesday to Friday. 
Table 1 Number of Observations

\begin{tabular}{|c|c|c|c|}
\hline $\begin{array}{c}\text { Bluetooth } \\
\text { Monitoring } \\
\text { Station }\end{array}$ & $\begin{array}{c}\text { Tuesday } \\
\mathbf{9 / 1 0 / 2 0 1 3}\end{array}$ & $\begin{array}{c}\text { Total } \\
\text { Records }\end{array}$ & $\begin{array}{c}\text { Unique } \\
\text { MAC } \\
\text { Addresses }\end{array}$ \\
\hline BMS-1 & 112,185 & 758,807 & 42,398 \\
\hline BMS-3 & 56,058 & 292,613 & 28,601 \\
\hline BMS-4 & 18,192 & 73,225 & 16,879 \\
\hline BMS-5 & 105,955 & 483,926 & 27,731 \\
\hline BMS-6 & 109,698 & 692,424 & 34,124 \\
\hline
\end{tabular}

\subsection{Penetration Rate}

A penetration rate analysis was carried out to find out the percentage of vehicles being identified using the sensors. The total volume count in southbound direction (Sardar Patel Road to Tidel Park), was obtained from an automated sensor. This was compared with the data from the three different sensors to obtain the penetration rate of each. Since these sensors can capture vehicles moving in both directions, the identified vehicles were first classified by direction and then the penetration rate was calculated. To identify the southbound vehicles from the Bluetooth hits, the difference in timestamps of the same MAC address detected at BMS 1 and BMS 6 were calculated. The addresses, with a positive difference, indicate that the vehicle travelled from BMS 1 to 6 . Only these addresses were used to compute the penetration in one direction of travel.

Traffax was able to capture $7.69 \%$ of the total traffic in one direction (Madhya Kailash - Tidel Park) whereas the Raspberry Pi was able to capture around 6.89\%, when both were equipped with a $13 \mathrm{dBi}$ antenna in off - peak conditions. The Android phone, on the other hand, was able to capture only $0.65 \%$ of the total traffic with its default Bluetooth radio. The penetration results give a clear indication that the Bluetooth sensors are a promising source of traffic information with a penetration rate of around $7 \%$, which can even extend to $10 \%$ during peak traffic conditions [3]. Table 2 shows the total hits as well as the unique hits for the three sensors along with their penetration rate. 
Table 2 Penetration Rate and Observations

\begin{tabular}{|c|c|c|c|}
\hline BT Sensor & $\begin{array}{c}\text { Android } \\
\text { Phone }\end{array}$ & $\begin{array}{c}\text { Traffax } \\
\mathbf{( 1 3 ~ d B i )}\end{array}$ & $\begin{array}{c}\text { Raspberry } \\
\mathbf{P i} \\
(\mathbf{1 3 ~ d B i})\end{array}$ \\
\hline $\begin{array}{c}\text { Penetration } \\
(\%)\end{array}$ & 0.65 & 7.69 & 6.89 \\
\hline $\begin{array}{c}\text { Total Hits } \\
\text { (for 27 } \\
\text { hours) }\end{array}$ & 2141 & 66,043 & 57,217 \\
\hline $\begin{array}{c}\text { Unique } \\
\text { Hits }\end{array}$ & 1282 & 8,447 & 8,189 \\
\hline
\end{tabular}

\subsection{Device Classification}

MAC address manufacture prefixes were analyzed to identify the class of the devices being observed. The first three octets of the MAC address representing the OUI were mapped with the IEEE database to determine the vendor/manufacturer of the detected devices. Fig 3a shows a pie chart representing the vendor classification obtained from the detected devices. It can be seen that, around $27 \%$ of the devices were Samsung whereas $20 \%$ belonged to Nokia, indicating that almost half of the detected devices belonged to the cell phone/smart phone category. Parrot SA is a French wireless products manufacturer involved in the development of Bluetooth hands free car kits and was $12 \%$ of the identified set. Car navigation systems such as Garmin only represented $0.27 \%$ of the total detections. Other smartphones such as Apple $(0.1 \%)$, Sony $(2 \%)$ and LG $(1 \%)$ showed very small representations, may be due to the fact that these devices, by default, remain in discoverable mode for only 120 seconds.

A similar classification using the MAC address was also carried out using a MAC address decoder based on the device detail provided by the Raspberry Pi and is shown in Fig 3b. It can be seen that $76 \%$ of the devices were mobile phones, of which $17 \%$ were smart phones and $59 \%$ cell phones. The audio/video devices in cars accounted to about $13 \%$ whereas the Bluetooth headsets varied from 2-4\%. Laptop computers only represented $1 \%$ of the total detections. This information can be used while trying to classify the vehicles into different modes. 


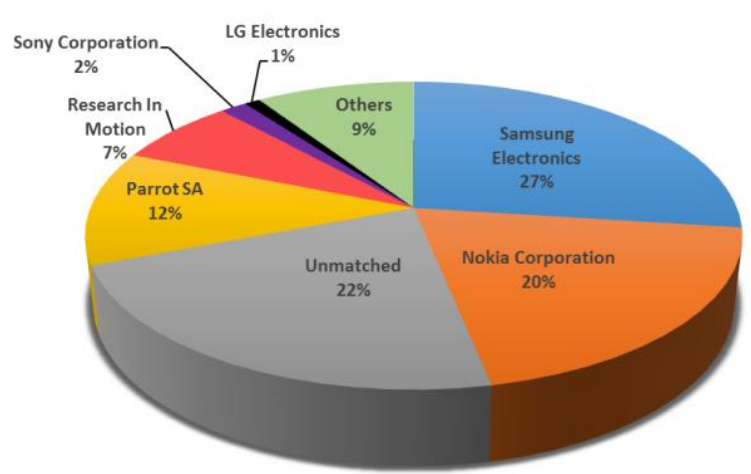

a. Vendor Classification

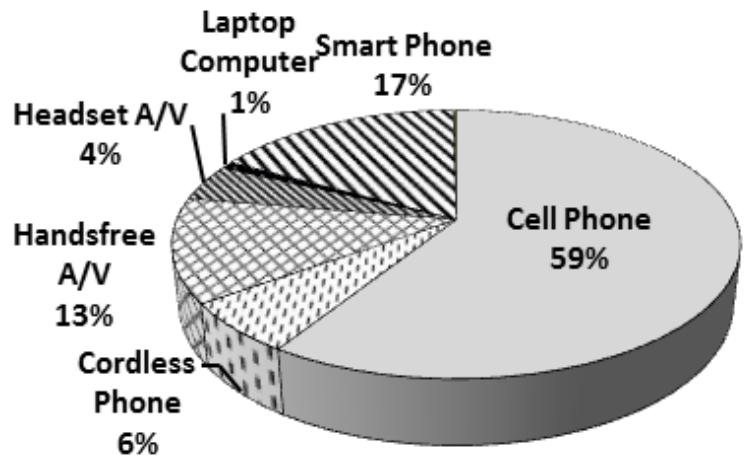

b. Device Type Classification

Fig 3 Bluetooth MAC address classification

\subsection{Travel Time Results}

The Bluetooth Monitoring Stations were used to determine the travel times between BMS 1 and BMS 5 on the corridor. A matching algorithm was used that matched the MAC address of a Bluetooth device between the two monitoring stations. The timestamps of the first detection of a Bluetooth device were used at both BMS 1 and BMS 5. These timestamps were then used to determine the travel times between the BMSs. These travel times were then plotted to determine temporal travel time characteristics both southbound (Fig 4a) and northbound (Fig 4b). The southbound direction was the direction of interest during this study with travel time peaks of nearly 30 minutes during the AM peak periods on Wednesday through Friday. The northbound traffic on the corridor was more consistent, but did have a 20 -minute travel time peak on Thursday. The study was developed to look at the southbound travel times, however using the same data sensors, the northbound travel times are also shown to understand the entire corridor.These two Figs. also display a significant amount of outlier data. These outliers can occur in Bluetooth data due to multiple reasons. There were a significant amount of pedestrians along the corridor, which could explain some of the outliers. There were also a significant amount of multi-modal traffic including busses, bicycles, motorcycles, and auto-rickshaws. Since Bluetooth data is point to point, there is also no guarantee that a vehicle did not stop part way through a trip and then continue to its destination. Different algorithms can be used to eliminate some of these outliers, but the preferred method is to include the outlier data and focus on the data trends. 


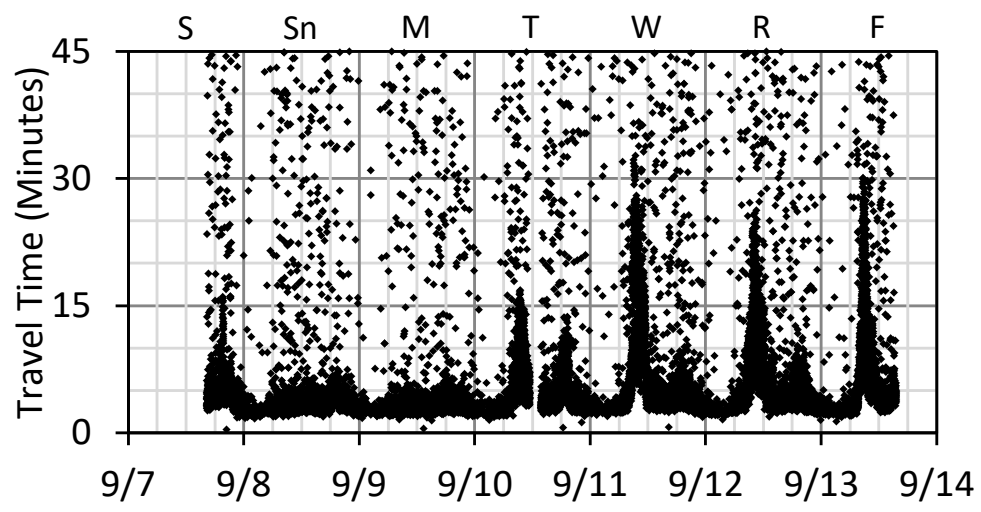

a. Southbound Travel Times

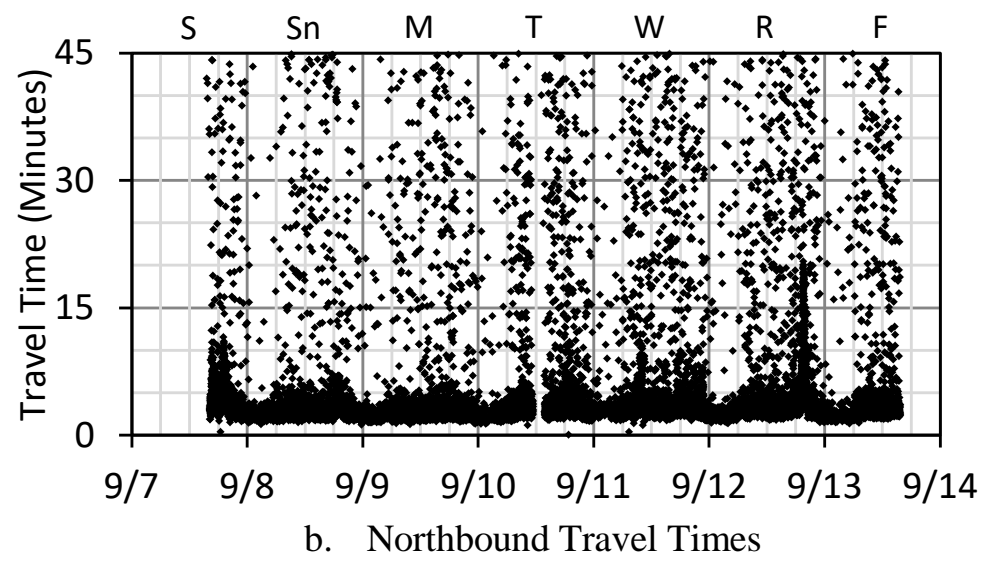

Fig 4 Scatter plots of Bluetooth travel time observations between BMS-1 and BMS-5

\subsubsection{Travel Time Plots for Identifying Time Periods with Highest Delay}

The week long temporal characteristics shown in Fig 4 are useful to determine extreme peaks in travel time. More robust characterizations of daily travel time along a corridor can be obtained by focusing on a single day. Fig 5 is a plot of data in both the southbound (Fig 5a) and northbound (Fig 5b) directions on a Thursday when rain was present for most of the AM period. The southbound direction AM peak period has a duration of over four-hours and a maximum travel time of approximately 25 minutes. The northbound direction PM peak period has a duration of approximately 1.5 hours with a maximum travel time of approximately 21 minutes. The northbound AM travel time was exceptional for this day and did not repeat the next day. The southbound travel time however was recurring over the last three days of data collection. Knowing the duration and maximum travel times of a given section of roadway is important to decision makers and engineers because it quantitatively assesses a roadway. This quantitative assessment can then be used to compare before and after a change in the network. These changes can include increased police presence, new road construction, signal timing improvements, or other traffic control devices. 


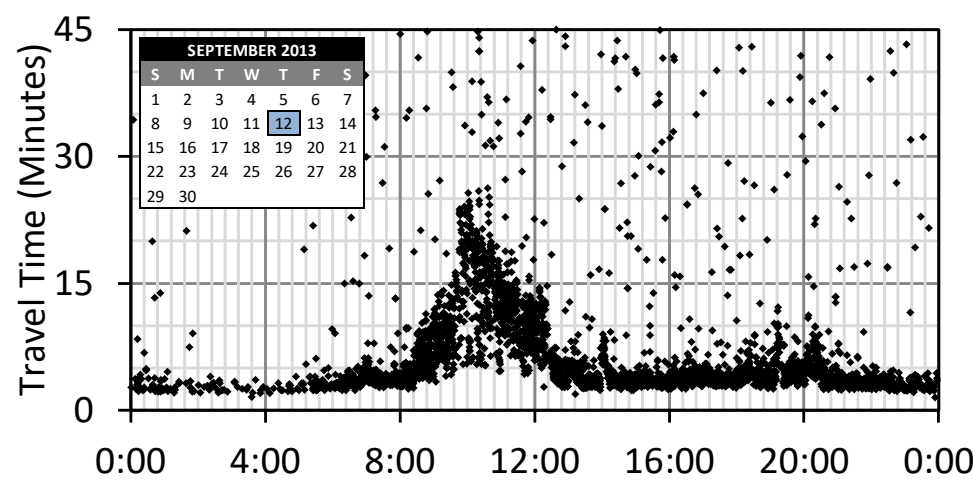

a. Southbound Travel Times

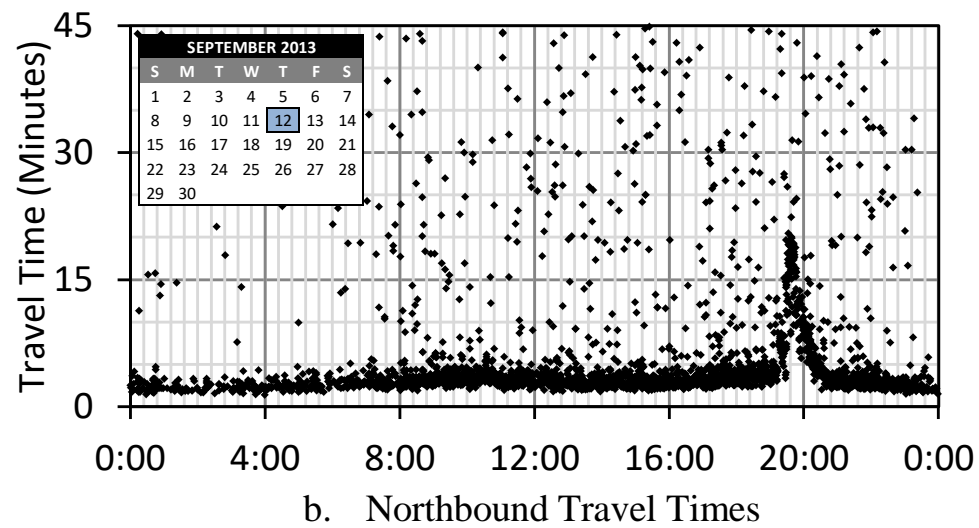

Fig 5 24-hour scatter plots of Bluetooth travel time observations between BMS-1 and BMS-5

\subsubsection{Travel Time Plots for Identifying Time Periods with Low Travel Time Reliability}

Longitudinal characterization of travel time and travel time variation along a corridor, throughout a day, can be performed by plotting median hourly travel times with interquartile ranges. These hourly interquartile ranges are plotted for the southbound (Fig 6a) and northbound (Fig 6b) directions. The benefit of plotting the interquartile range is the elimination of the outlier data that can be seen in Fig 4 and Fig 5 . Fig 6 provides a very clear story about the travel time along the corridor. Fig 6a displays elevated southbound travel times between 0800 and $1300 \mathrm{hrs}$. It also shows an increased interquartile range as the median travel time increases. A small interquartile range value represents a very reliable corridor, meaning that most vehicles are experiencing the same travel time while traversing the corridor. As the interquartile range increases the travel time becomes unreliable, meaning that vehicles are not experiencing the same travel time when traveling the corridor. A goal of traffic engineers is to provide reliable travel times along a corridor and these Figs. allow a graphical performance metric to evaluate that goal. 


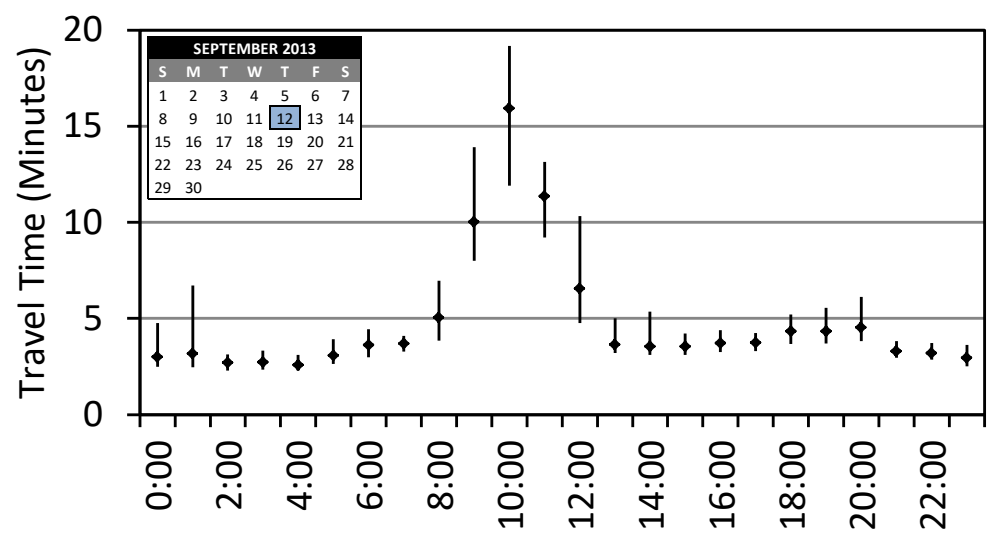

a. Southbound Travel Times

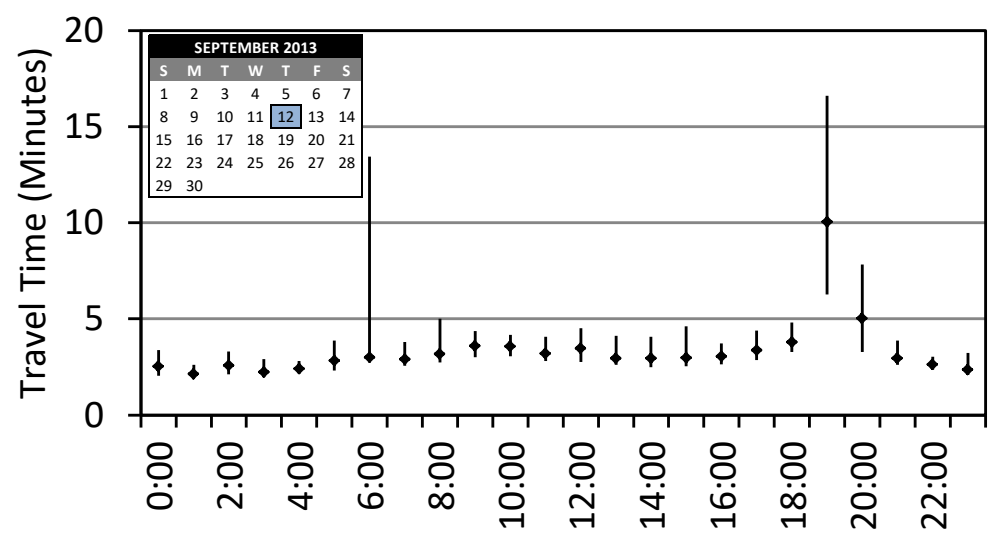

b. Northbound Travel Times

Fig 6 Hourly quartile stock plots of Bluetooth travel time observations

An additional plot that can be used to represent the travel time information along a corridor is cumulative frequency diagrams, or CFDs. Cumulative frequency diagrams were created for each hour of the day during the study period. Fig 7 shows the 10:00 hour for each day of the study period. There is a clear pattern in the six hourly travel times in Fig 7. The travel time CFDs for September 8th and 9th, a weekend and a holiday respectively, mirror each other. Both those days have median travel times near the free flow travel time for the corridor and a near vertical slope which is an indication of exceptional travel time reliability. The CFDs for September 10th and 13th are the next two days which have very similar travel time patterns. Both Tuesday, September 10th and Friday, September 13th are typical weekdays on the study corridor. The median travel time for the 10th is 7 minutes and for the 13th is 8.5 minutes. The slope of these two lines are flatter, indicating the travel times are less reliable on the 10th and 13th, which is expected because they are during a weekday and there are more vehicles than on a weekend or holiday. 


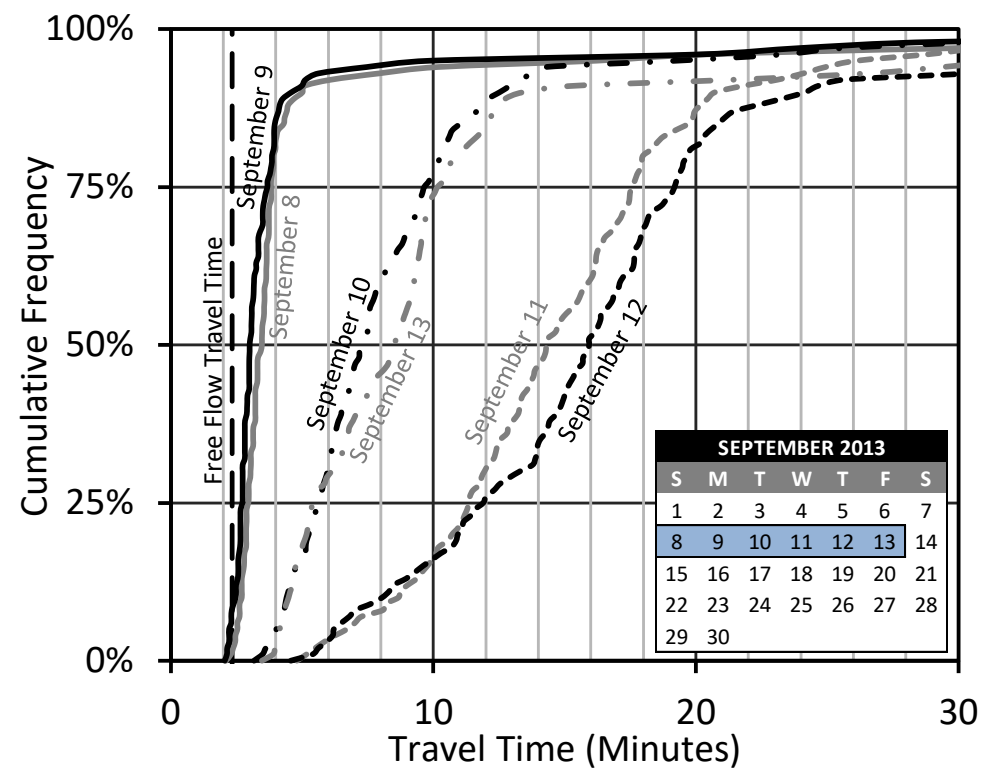

Fig 7 Cumulative frequency diagrams of Bluetooth travel time observations for the 1000 hour of each day

The final group of CFDs are for the 11th and 12th of September, which are a Wednesday and Thursday, respectively. The median travel times for these two days are between 14 and 16 minutes, which is significantly higher than the other weekdays and over 11 minutes higher than the free flow travel time of the corridor. Looking at the relative humidity from the two days, during the 1000 hour, there was a relative humidity level of over $102 \%$ for both the 11th and 12th. Fig 8 is a histogram of the 10 AM relative frequencies throughout the study week. A relative humidity of greater than $100 \%$ indicates there was rain during these periods. The rain in the period caused more delay on the corridor and also resulted in less travel time reliability across the segment.

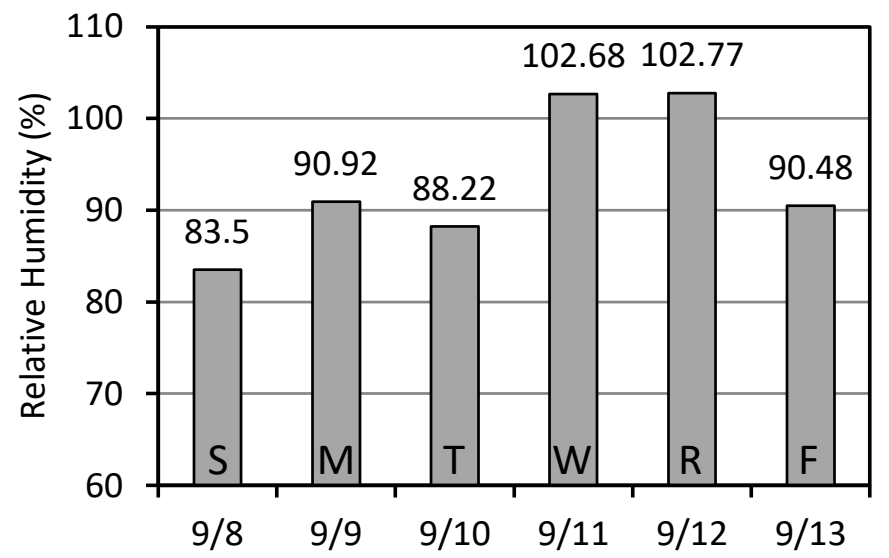

Fig 8 Relative humidity in Chennai, India (September 8- 13, 2013)

\subsubsection{Travel Time Plots for Identifying Locations with Highest Delay}

Another approach involving CFDs is using all of the Bluetooth monitoring stations on the corridor to determine where the delay occurs. Fig 9 shows southbound data from matching BMS 1 to BMS 3, 4, 5, and 6 for three different morning periods (0900-1200) during the study week. The first is on Monday, September 9th, which was a holiday in India (Fig 9a). The four CFDs in this figure are very reliable 
showing very consistent travel times throughout the corridor. Fig 9b shows the travel time data from a weekday when there was no rain. The travel times between BMSs $1 \& 3$ and BMSs $1 \& 4$ show similar reliability, however between BMSs $4 \& 5$ there appears to be something that is causing a delay. Using video footage from the corridor it was possible to determine that the reason for the delay was a long queue from the southern-most intersection. Fig 9c represents a weekday on the corridor when there was rain. This figure is very similar to Fig $9 \mathrm{~b}$ except it appears the travel times are slower. This is expected because drivers perceived some risk due to the rain causing them to slow down. These figures are valuable for understanding where problems occur on a corridor.

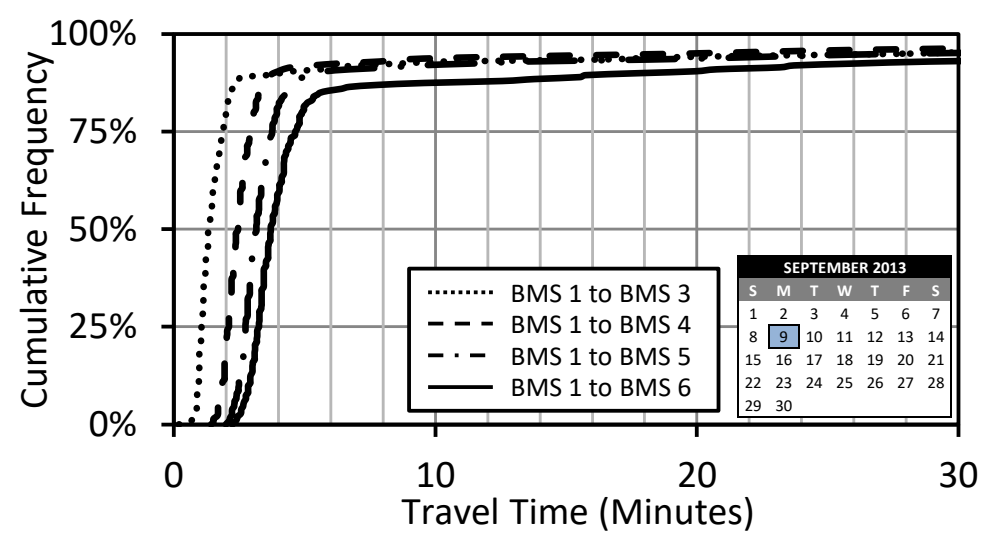

a. Monday, September 9, 2013 0900-1200

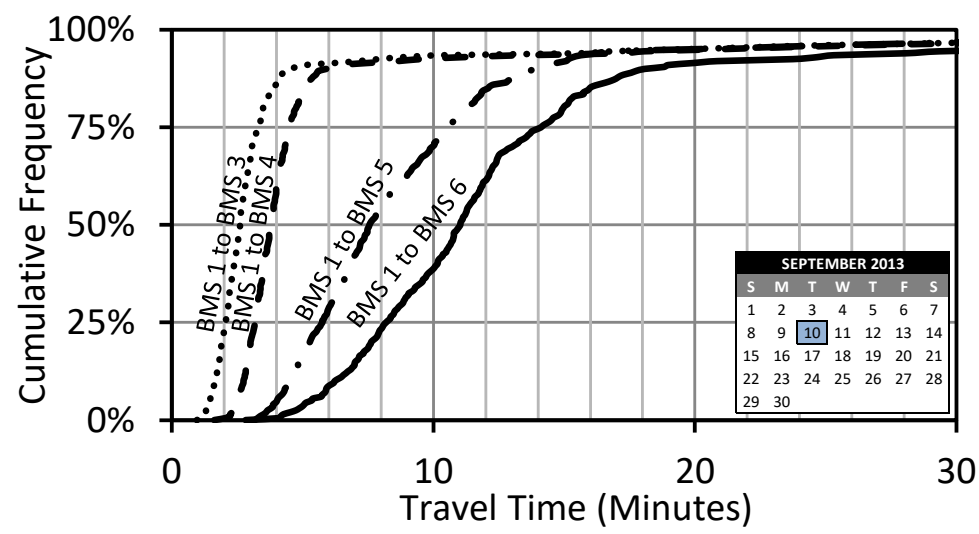

b. Tuesday, September 10, 2013 0900-1200

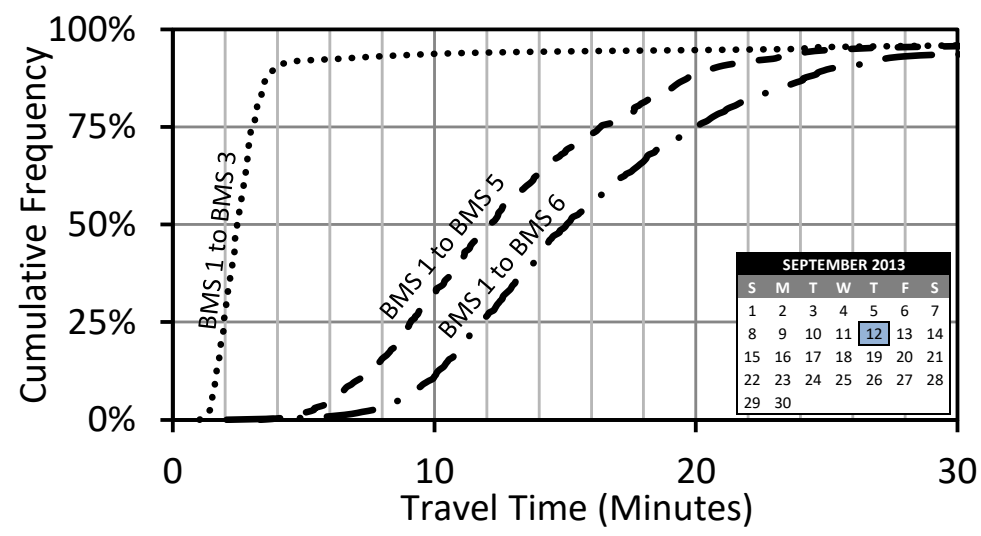

c. Thursday, September 12, 2013 0900-1200

Fig 9 Segmental cumulative frequency diagrams of travel times 


\section{CONCLUSIONS}

Bluetooth Monitoring Stations have been well-documented in the United States and provide very valuable data to understand traffic conditions along various classes of roadway. This paper examined the usefulness of Bluetooth monitoring on a corridor in Chennai, India. There are very different traffic patterns and modal splits in India, which result in a very interesting study corridor. The result of this study demonstrate that the Bluetooth data could be used in India and that the data fidelity collected on this corridor appeared to be superior to that of studies performed in the United States and other regions of the world. Over 147,000 unique daily MAC addresses were collected and used to assess the characteristics of the Rajiv Gandhi Salai corridor. During a week of data collection, three significantly different traffic characteristics were observed in the southbound direction in the AM period:

- Weekend/Holiday Traffic

- $\quad$ Typical Weekday Traffic

- Weekday Traffic with rainy weather conditions

Queuing at the Tidel Park intersection (southern-most) seemed to have caused a majority of the delay on the corridor during a typical weekday. During adverse weather conditions, the median travel time along the southbound corridor nearly doubles. A future study could be performed by changing the traffic control characteristics at the Tidel Park intersection and using this study as initial data and recording new Bluetooth data to determine the effect of changing the traffic control.

\section{ACKNOWLEDGMENTS}

The authors acknowledge the support provided by Indo-US Science and Technology Forum (IUSSTF), Government of India under the grant IUSSTF/JC-Intelligent Transportation Systems//95-2010/2011-12. The contents of this paper reflect the views of the authors, who are responsible for the facts and the accuracy of the data presented herein, and do not necessarily reflect the official views or policies of the sponsoring organizations. These contents do not constitute a standard, specification, or regulation. 


\section{REFERENCES}

[1] Wasson, J.S., J.R. Sturdevant, D.M. Bullock (2008), "Real-Time Travel Time Estimates Using MAC Address Matching," Institute of Transportation Engineers Journal, ITE, Vol. 78, No. 6, pp. 20-23. Accession Number: 01108548

[2] Haghani, A., M. Hamedi, K.F. Sadabadi, S. Young, P. Tarnoff (2010). "Data Collection of Freeway Travel Time Ground Truth with Bluetooth Sensors," Journal of the Transportation Research Board, No. 2160, Transportation Research Board of the National Academies, Washington, D.C., pp. 60-68. DOI: $10.3141 / 2160-07$.

[3] Brennan, T.M., J.M. Ernst, C.M. Day, D.M. Bullock, J.V. Krogmeier, and M. Martchouk (2010), "Influence of Vertical Sensor Placement on Data Collection Efficiency from Bluetooth MAC Address Collection, ASCE Journal of Transportation Engineering, Vol. 136, No. 12, pp. 11041109. DOI: 10.1061/(ASCE)TE.1943-5436.0000178.

[4] Martchouk, M., F.L. Mannering, and D.M. Bullock (2011), "Analysis of Freeway Travel Time Variability Using Bluetooth Detection,"ASCE Journal of Transportation, Vol. 137, No. 10, pp. 697704. DOI: 10.1061/(ASCE)TE.1943-5436.0000253.

[5] Haseman, R.J., J.S. Wasson, and D.M. Bullock (2010), "Real-Time Measurement of Travel Time Delay and in Work Zones and Evaluation Metrics Using Bluetooth Probe Tracking," Transportation Research Record: Journal of the Transportation Research Board, No. 2169, Transportation Research Board of the National Academies, Washington, D.C., pp. 40-53. DOI: 10.3141/2169-05.

[6] Hainen, A.M., J.S. Wasson, S.M.L. Hubbard, S.M. Remias, G.D. Farnsworth, and D.M. Bullock (2011), "Estimating Route Choice and Travel Time Reliability with Field Observations of Bluetooth Probe Vehicles," Transportation Research Record: Journal of the Transportation Research Board, No. 2256, Transportation Research Board of the National Academies, Washington, D.C., pp. 43-50. DOI: 10.3141/2256-06.

[7] Barceló J, Montero L, Bullejos M, Serch O, Carmona C. (2008), "A Kalman Filter Approach for the Estimation of Time Dependent OD Matrices Exploiting Bluetooth Traffic Data Collection.", Journal of Intelligent Transportation Systems: Technology, Planning and Operations, Vol. 17, No. 2, pp. 123-141. DOI: 10.1080/15472450.2013.764793.

[8] Remias, S.M., A.M. Hainen, C.M. Day, T.M. Brennan, H. Li, E. Rivera-Hernandez, J. Sturdevant, S.E. Young, and D.M. Bullock (2013), "Performance Characterization of Arterial Traffic Flow with Probe Vehicle Data," Transportation Research Record: Journal of the Transportation Research Board, No. 2380, Transportation Research Board of the National Academies, Washington, D.C., pp. 10-21. DOI: $10.3141 / 2380-02$.

[9] Haghani, A., M. Hamedi, and K. F. Sadabadi. "I-95 Corridor Coalition Vehicle Probe Project," University of Maryland, College Park, Jan. 2009.

[10] Blogg, M., C. Semler, M. Hingorani, and R. Troutbeck, "Travel Time and Origin-Destination Data Collection using Bluetooth MAC Address Readers," Australasian Transport Research Forum 2010 Proceedings. 29 September 2010.

[11] Jie, L., H. Zuylen, L. Chunhua, L. Shoufeng (2011), "Monitoring Travel times in an urban network using video, GPS, and Bluetooth," Procedia Social and Behavioral Sciences, Vol. 20, pp. 630 637, DOI: 10.1016/j.sbspro.2011.08.070

[12] Versichele, M., T. Neutens, M. Delafontaine, N. Weghe (2012), "The use of Bluetooth for analyzing spatiotemporal dynamics of human movement at mass events: A case study of the Ghent Festivities," Applied Geography, Vol 32, No. 2, pp. 208 - 220, DOI: /10.1016/j.apgeog.2011.05.011. 